\title{
Segregation of Job Duties and Types of Personalityin Responding the Risks
}

\author{
Antonius Bimo Rentor, Amelia Setiawan ${ }^{\bowtie}$, Gery Lusanjaya \\ Faculty of Economics, Universitas KatolikParahyangan, Indonesia \\ Jl. Ciumbuleuit 94, Bandung 40141, Indonesia \\ DOI: http://dx.doi.org/10.15294/jda.v9i1.11999
}

Received: 13 October 2016. Revised: 1 December 2016. Accepted: 6 February 2017. Published: 31 March 2017

\begin{abstract}
This study aims to analyze the implementation of tasks separation associating with analysis of personality. The object in this study consists of organizational structure and job description of employees in a credit department at one of the banks in Indonesia. This research uses a descriptive method that designed to collect data that describes characteristics of an interesting variable in a certain situation. Data collection consists of literature studies and field research and specific techniques that developed from field research including interviews, questionnaire collection, and field observation. The results show that placement of employees related to functions separation at Relationship Banking Officer unit in credit department does not meet management expectations. This unit has too many employees with various personality types and different respond to risks. Meanwhile, the employee placement at Account Officer unit in credit department has met the management expectation as well as the employee placement at Administration Staff Credit unit. It can be concluded that the procedure of function separation in credit department has been done in accordance with the criteria of the management.
\end{abstract}

Keywords: Risk Response; Segregation of Duties; Types of Personality

How to cite (APA 6th Style)

Rentor, A. B., Setiawan, A., \& Lusanjaya, G. (2017). Segregation of Job Duties and Types of Personalityin Responding the Risks. Jurnal Dinamika Akuntansi, 9(1), 49-62.

\section{INTRODUCTION}

Certain phenomena occuring from various banking companies lately shows that the segregation of duties that runs within the companies is not much fit with the expected development progress. One of the growing phenomena related to this segregation is multiple positions/ functions. The multiple position state in the segregation of the duties is basically allowed if this is done as a form of risk management with reasonable limits as set out in Bank Indonesia Regulation Number 8/4 / PBI / 2006 on the Implementation of Good Corporate Governance for Commercial Banks. The multiple positions widely applied in various companies today tend to cause various risks that may harm the companies from various viewpoints.

Based on the observations posted in Kompasiana in a rubric entitled "Multiple Position Phenomenon in this Country" in 2015, the basic risks that may arise with the application of the multiple positions in the companies are ignorance and abuse of authority. These can have a negative

Amelia Setiawan $(\square)$

E-mail: amelias@unpar.ac.id 
impact by disrupting the stability of the corporate activities to achieve common organiational goals. The negative impact of these risks can be solved by analyzing various risks associated with the multiple positions as a part of segregation of duties that may occur in a department of the company, then adjusting the process segregation to align with the corporate goals. Internal control is an inherent concept within information systems of a company. Good internal control represents good corporate quality in front of the public as well as other competitors in the business world. Internal control is one of the concepts that need to be understood in providing adequate assurance for the company in carrying out its activities.

One of the key components of internal control is control activities. The procedure of control activities many companies apply is the segregation of duties. This procedure is important in increasing employees' commitment and preventing various frauds contrary to the process of achieving the common corporate objectives. This segregation process almost always exists in various business fields with various scales of companies, from small, medium, to large scale enterprises. The focus of a company regarding the segregation of duties generally lies in various activities that need to be segregated from various existing possibilities. The human concept that supports the continuity of this procedure is often set aside that causes the decrease in the effectiveness of the assessment of the segregation process.

The human as one component in the accounting information system associated with the segregation of duties itself should be able to form a new rationale that can improve the quality of assessment related to the effectiveness of segregation procedures of various existing companies. One type of companies that should pay attention more thoroughly to the procedure of segregation of duties and be associated with the concept of human is the banking companies.

The controlling activities is one component of the internal control. The internal control is a planning process within the company, all methods used are neatly coordinated, certain measurement techniques used to maintain the security of its assets, checking the accuracy and reliability of its accounting data, improving the efficiency of its operations, and encouraging to be compliance with the provisions in managerial policies to present adequate certainty in relation to the process of achieving the corporate goals (Moeller 2008; Arens et al., 2014, p.312). The controlling activities as one of the internal control components includes some policies and procedures used to ensure that directions from the top management are implemented properly. Many of the corporate control activities that can be practically applied are accounting and compensatory controls.

This accounting control is a form of control activities used by the company to provide reasonable certainty regarding the conformity of control objectives using application system. Compensative control is a control process that depends on the firm nature (flexible). In other words, such control is able to adapt the corporate environment in which the control is implemented. The control procedure consists of several categories including proper authorization process, segregation of duties, project control development, management control changes, design and use of corporate records or documents, assets protection in the form of data or records, and independent checks.

The segregation of duties as one of the control procedures is undertaken to ensure that every employee within a company does not bear excessive responsibilities that may affect the overall performance quality. Two types of segregation of duties commonly applied in a company is the segregation of accounting functions and the segregation of the duties related to the information systems. The focus of this study rests on the segregation of accounting functions that occur in the company by considering the preferences of each employee related to their risk responses. The segregation of the accounting functions within a company basically classifies the works performed by the employees into five main duties consisting of authorization, storage, recording, examination, and execution duties (Vaassen et al., 2009). Good segregation of duties in a company is generally indicated by the minimal number of multiple positions assigned to particular employees. It is better that each of the duties above should be handled by different 
individuals.

The segregation is also done to reduce the possibility of frauds committed by unscrupulous employees. The process of grouping employees into five types of personality will be undertaken in examining risk-related preferences to maximize the assessment of the segregation of suties in the company in order to improve the quality of internal controls. The responses toward the risk that become one of the fundamentals of this study consist of four alternatives. They include reduce, accept, share, and avoid. Reduce is an alternative done by reducing the tendency and impact of a risk by implementing an effective internal control system. Accept is an alternative done by accepting the tendency and impact of a risk. Share is an alternative done by dividing the risks the company has with other related agencies such as insurance and outsourcing companies. Avoid is an alternative where the company does not do anything that may rise the risks.

The types of personality which also acts as a benchmark in this research is a human-related concept as one component of accounting information system related to the internal control. Each type of personality is a studied part of an organizational behavior. The organizational behavior is a study that examines many factors influencing the behavior of individuals and groups within an organizational environment (George and Jones 2002, p.6). The organizational behavior is an important element to be considered by the management within a company to show high appreciation for each completed duty. The organizational behavior can also assist the managers within a company in grouping the duties to all employees. Personality is a pattern that shows how a person feels something, thinks about something and behaves in his/her environment (George and Jones 2002, p.43). The personality has an influence on career choices to be taken, job satisfaction, stress level, leadership, and some other aspects related to one's works.

The personality of each person can basically change along with the age and the increase of life experiences that form a new mindset before taking an action. This suggests that determinant of someone's personality is not only derived from natural genes owned since he/she were born, but also from his/her life experiences. Therefore, each individual basically has not only one particular character or type of personality. Each individual can have a composite of several unique types of personality as the differentiating factors.

The determinants of the types of personality that differentiate between one with another consist of nature and nurture. Nature and nurture itself are the decisive factors that can be converted to determine an individual's overall personality. Trait is a term related to the concept / understanding related to one's personality. One model that can describe the trait related to this personality is the big five model of personality or also commonly called as five-factor model (FFM). This personality model is a simplified form of each individual trait (McCrae 2002, p.3). This model places five general categories of one's personality including extraversion, neuroticism, agreeableness, conscientiousness, openness to experience. These five general categories of personality are universally applicable structures that can be applied in various types of crosscultural personality studies.

The focus of this study is the analysis of the management criteria conformity with the real conditions related to the quality of the segregation of the duties procedure determined through the analysis of individual characters in the organization related to the responses to risk. This analysis can help the company to assess the degree of effectiveness of the segregation of duties by looking at the human as an important factor influencing the success of the procedure. Individual human characters in the organization (employees) become an important factor because they are the main driver of corporate activities in achieving its goals. If the individuals in the organization have good quality, then the activities can be implemented according to the criteria. An individualrelated character that can be studied to improve the quality of the segregation is personality. The personality of each individual can show appropriate patterns / trends related to the works that can be done to fulfill the corporate goals.

This research is interesting to do because it's related to the separation of functions with the key is human-based personality is still rarely done because during this separation of tasks only 
focused on the management criteria set after the employee is in a certain positionThis research will be conducted on one of the largest banks in Indonesia which focuses its activities on micro, small and medium enterprises loans (SMEs). The research will be focused on the credit department which is the main generator of the corporate activities in one of its branches. The purpose of this study is to present a new analytical medium in assessing the suitability of the application of the segregation of duties to the criteria expected by the management by looking at the human as an important determinant. The discussion in this study focuses on the procedure of segregation of duties as a form of control activity associated with the analysis of risks, and individual personality as a determinant of the effectiveness of the assessment toward current procedure.

\section{METHODS}

The method used in this research was descriptive. Descriptive research was a method designed to collect the data that described the characteristics of an interesting variable in certain situations. This method would provide a detailed explanation of the research objects based on the data obtained. The data needed in this research process consisted of qualitative data and quantitative ones. The qualitative data were divided into the corporate job description, organizational structure, and company profile that provided an overview of the basic principles developed by the company. Meanwhile, the quantitative data included resuts of the questionnaires distributed to the employees of the Department of Credit from one of Indonesia's leading banks in Bandung during the research process, including statistical data that helped the collection process. The data collection techniques used were literary and field studies. The literary study was applied by studying the object through textbooks, journals, and corporate documents.

Textbooks were basically used to study the theories related to the objects studied, while journals and corporate documents were to support the research conducted according to the available theories. Field study, which was the second data collection technique, was done by observing directly the activities of the objects and collected as much as information needed directly from the related parties. The specific techniques developed from this field study include interviews, questionnaire collection, and field observation.

This research was initiated by determining the topic. The topic raised in this study was closely related to the analysis of segregation of duties criteria assessed from the types of personality and individual responses toward the risks arising from particular activities. The next stage was connected to the process of identifying the problem formulation of the topic. The main problem of this study related to the analysis of the suitability of the segregation of duties applied by the company with certain criteria expected by the management. The next stage was to determine the steps of the research to obtain necessary conclusions.

The research steps include: (1) asking for the job description used by the company, (2) analysis of job description to find the presence or absence of multiple positions in the company, (3) risk analysis which might occur if there are any multiple positions, 4) analysis of individual risk-related responses related to the types of personality, (5) interviewing the management related to their expectations of segregation of duties process, and (6) analyzing the suitability of criteria of segregation process applied by the company with the criteria expected by the management thoroughly.

After determining the steps mentioned above, the next was to determine the research variables. The research variables consist of independent and dependent ones. The independent variables found in this research were types of personality and employees' response toward the risks of an activity. Meanwhile, the dependent one in this study was the segregation of duties. The analysis conducted in this research consisted of literary and field studies. The literature study was an analysis process related to some efforts to understand deeply the research objects study from existing sources such as internal control theory, personality theory, and job description applied by the company at this time. 
Meanwhile, the field study was an analysis process related to everything that might happen in the field and studied through the process of observation, collection of questionnaires, as well as interviews conducted on the management as described in the previous section. The research objects in this study were the organizational structure and job description of the employees in the credit department.

The data collection was done within three ways, namely: (1) interview, (2) questionnaire, and (3) observation. Interview was a data collection technique conducted with the aim of collecting various information related to the research problems. This interview was applied by conducting question and answer sessions with the management to obtain supporting information needed related to the research. The type of interview conducted in this study was structured interview, because a list of questions that would be used had been made first to ensure the purpose of the interview could be achieved. The records of the interview results made directly during the process were included in the appendix section. The questionnaire was a technique used by the respondents to answer a set of questions posed on a particular study. The questionnaire was distributed to obtain the required information from a part through each respondent contained therein.

The questionnaire in this study was used to obtain information related to the types of personality and individual ways in responding to the risks on the parts of RBO, AO, and ADMK of the company. List of questionnaire questions and their recapitulation could be seen in the appendix. Observation was a process of seeing directly the activities that occured in the company. The observation in this study was conducted to ensure the divisions of works were in accordance with the job description owned by each existing section. In addition, this observation was also conducted to ensure that the three parts of $\mathrm{RBO}, \mathrm{AO}$, and ADMK fully supported the corporate credit activities as explained in the description of existing corporate positions. This research was conducted using a case study at a bank in Indonesia which had 280 branch offices spread over 22 provinces. The bank as the research object had conducted Initial Public Offering (IPO) in July 2006.

\section{RESULTS AND DISCUSSION}

The main analysis related to this research is started from the analysis of corporate job description. The job description analysis performed on the company will focus on the employees of the credit department. The employees of the credit department are re-grouped into three small sections consisting of Funding Banking Officer (RBO), UKMK Business Division, Account Officer $(\mathrm{AO})$, as well as the services and operational section i.e. Credit Administration Staff (ADMK staff). The analysis will be done by grouping the job descriptions of the employees mentioned above into the general and specific ones. The general job description group contains details of the employees' responsibilities from all departments. Meanwhile, the specific job descriptions contain details of the employees who are specialized in dealing with specific sections within each department.

The analysis through this grouping process aims to assist the process of identifying multiple functions contained in each section in a department that performs its own specific key functions. These multiple functions analysis is required to identify potential risks that may arise in every part of a department related to its executed functions. The general job descriptions contained in the three parts of the company are connected to the compliance of ethical code, the implementation of personal development activities related to their respective expertise, and the implementation of other various assignments that support the main activities within their respective sections.

The general job descriptions for RBO, AO and ADMK staffs are: (1) to understand and comply with the ethical code, corporate culture and regulations to maintain business sustainability and harmony of relationships among sections and employees; (2) to proactively make efforts (including improvement of understanding toward products knowledge and selling skills) to ensure fulfillment of job-related competencies requirements; (3) to perform other assignments 
as required and / or directed (e.g. providing input to the distribution network and consumer business development divisions for network expansion / new outlet proposals).

Meanwhile, the specific job descriptions contained in the RBO section focus on fostering good relationships with the customers as well as a form of marketing efforts in order to maintain the corporate growth rate. The specific job descriptions contained in AO section emphasize on overall credit verification process, starting from credit feasibility analysis to credit disbursement decisions. The specific job descriptions contained in ADMK focus on the overall credit administration process. The whole process includes reassessing the feasibility analysis of the debtor candidate, approving the credit distribution to particular parties, and maintaining good relationships with the debtors who are the corporate customers. The main focus of RBO leads to the customer acquisition through marketing activities. This section requires the employees who act as the marketers of banking products offered by the company. The banking products concerned are specifically related to the provision of credit to the micro, small, and medium enterprises (MSME). In addition to being responsible in obtaining the customers through marketing activities, $\mathrm{RBO}$ employees have also a responsibility to retain the customers who have worked with the company.

The responsibilities related to this matter can be seen from the activities of managing the customer portfolio, solving problems found in certain customers, establishing good relationships with the customers, as well as other activities that prioritize the interests of the customers in carrying out the activities thoroughly. The main responsibility of $\mathrm{AO}$ is the process of verifying overall credit activities. This process includes creditworthiness analysis, supervising the crediting process, solving credit problems, and improving the credit quality required by the company in order to achieve its missions and visions related to the existing credit distribution. The responsibility for conducting crediting activities analysis does not only focuses on the feasibility analysis of the debtors before applying for credit, but also analysis of certain conditions that arise when and after the company distributes the credit. It aims to ensure credit payment and quality of credit owned by certain customers is in accordance with the terms applied and is considered not to harm any party.

Meanwhile, the main focus of the ADMK staffs' responsibility is more on the credit approval process. Any form of credit-related implementations that have been verified first in the AO section is run by ADMK staffs. This implementation starts from authorization process to the credit distribution to the debtors. ADMK staffs also have the responsibility to examine prospective debtors as conducted by AO. This is done to make sure the company has reasonable confidence in the prospective debtors who are trusted to obtain credit to run their own businesses.

The job descriptions grouping in each section are used to understand the process of segregation of duties run by the company in each section in the credit department. Analysis of the implementation of the segregation of duties is done by adjusting the descriptions of the specific positions of each section with the criteria of segregation based on Vaassen theory. Based on the research conducted, the segregation of duties performed by the company has not been in accordance with the expected segregation criteria. Almost every section has its own multiple functions. The RBO section has multiple functions consisting of execution and recording functions. $\mathrm{AO}$ has a triple functions consisting of execution, recording, and checking functions. Meanwhile, the ADMK section has four functions including authorization, execution, checking, and recording functions. This multiple functions can create potential risks that may harm the company.

The execution and recording functions contained in $\mathrm{RBO}$ arise from some main specific responsibilities. The execution function arises from marketing execution activities consisting of exploring the business potential of the customers, striving for customers' satisfaction through the specifically priority banking products offered, marketing all banking products, conducting sales references, as well as performing various things needed to improve the marketing activities. Meanwhile, the recording function arises from the recording activities performed by the section 
that is directly related to the activities performed. The recording is generally done related to the activities undertaken by the employees and the preparation of feasibility evaluation of potential marketing targets for the sustainability of the company.

The execution, checking, and recording functions contained in $\mathrm{AO}$ section arises from some main specific responsibilities. The execution function arises from the credit verification activities conducted by the employees, which include exploring the potential of the customers' businesses as well as establishing good relationships with the customers, analyzing the loan applications, performing the entire credit process based on prevailing principles, and resolving various credit issues that arise according to the applicable credit settlement guidelines. The checking function arises from supervisory activities performed on prospective credit recipients and debtors. These supervisory activities cover monitoring the progress and conditions of the debtors' businesses to ensure the repayment and credit quality in accordance with banking regulations. Meanwhile, the recording function arises from the activities of making reports consisting weekly and annual reports which contain the quality of target achievement of the relevant section.

The authorization, execution, checking, and recording functions of the ADMK staffs arise from some key specific responsibilities. The authorization function in this section arises from lending approval activities to the debtors' applicants for liquefaction, reduction, extension, restructuring, withdrawal, or credit repayment. The execution function arises from activities executed according to the given consents. The recording function arises from reporting activities including preparing general bank report, preparing income tax report chapters $21 / 23$, preparing proofsheets, and preparing reports on the debtors' data as well as updating the debtors' data periodically, completely, and accurately. The checking function arises from the examination activities consisting of examining the debtors' data and the credit documents, and monitoring the archives of the debtors conducted each month.

Risk is a form of uncertainty that occurs as a consequence of ongoing processes/events. The uncertainty that emerges can be either positive or negative. The risks arising from the multiple functions/jobs of the company are generally addressed by every section of the department differently. The risks that may occur related to the segregation of duties are divided into two groups; basics and advanced risk. Basic risks are those arising from double functions for each function within the company. The basic risks are the basis for the formation of further risks that arise as a result of triplicate or more functions related to the segregation of the functions implemented by the company and already occur in every section of the credit department. The following is a risk scheme that may arise from any multiple functions found in the company, hereinafter referred to as risk star. This risk star is adjusted to the risks arising from the multiple duties or function that may occur in each section of the company's credit department. The risk scheme of duplicate functions in the corporate credit department is shown in Figure 1.

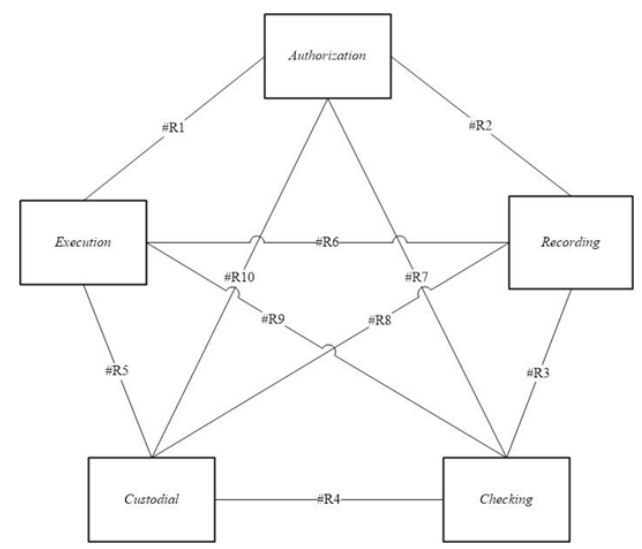

Figure 1. Risk Scheme of multiple Job Duties in the Credit Department (Risk star) Source: Author's processed data 
The basic risks in the company arise as a result of the multiple duties/function of the execution the recording in RBO. The basic risks are those associated with falsifying the feasibility report of network expansion through the prospective debtors (\# R6). Meanwhile, the other nine basic risks form the basis for the establishment of further risks. The first risk arises from the multiple functions between the authorization and the execution. The risk of this condition is related to the approval of overly large nominal credit transactions. The approval of these credit transactions may result in non-performing debtors related to the quality of loan repayment by the corporate customers. In addition, this may lead to a decrease in the overall quality of credit distribution as it demonstrates the company's weakness in selecting prospective debtors. The second risk arises from the multiple functions between the authorization and the recording. The risk of this state is related to fraudulent records. The fraudulent record means the risk of counterfeiting the records of an activity that is not in accordance with applicable corporate procedures. The inconsistent activities which are not based on corporate procedures are the form of illegal credit transactions that can be detrimental to the company as a whole.

The third risk occurs from the multiple functions between the checking and the recording. This issue is related to the risk of counterfeiting the observation results by an employee of a section within particular department. The observations that are at risk of falsification are those related to the feasibility of the debtors' candidate needed to facilitate the credit distribution as the main activity in the credit department. The fourth risk arises from the multiple functions between the checking and the custodial. The risk of this dual functionality is related to the data storage that does not match with the facts. The false data storage that may harm the company is the mismatch of the debtors' feasibility analysis with the real analysis data. This improper storage of data may pose the company's loss related to the credit misalignment to the wrong parties.

The fifth risk arises from the multiple functions between the execution and the custodial. The risk is related to non-qualified credit approval. This may occur if the gap of information related to the debtors who are currently cooperating with the company is used to make as if the debtors deserve credit from the company. The sixth risk arises from the dual functions between the execution and the recording. The risk of this dual function is related to the risk of falsifying the evaluation report. The evaluation report shows the feasibility of network expansion through the procurement of new debtors. This can be done by manipulating the recording of evaluation data related to the debtors that should not meet the company's requirements and may harm the company related to the repayment problem in the future.

The seventh risk arises from the multiple functions between the authorization and the checking. The risk of this condition is related to the credit extension approval from the debtors that no longer meet the eligibility standards or criteria for obtaining credit extension from the company. The extension of loans granted to the debtors under the conditions of eligibility may result in potential losses related to the level of corporate liquidity due to the decreasing quality of repayment. The eighth risk arises from the dual functions between the custodial and the recording. It is related to the risk of manipulation of important information owned by the company. This may result in potential loss of certain information / data due to the theft of internal parties to be sold to external ones. The theft of this data can harm the company in an effort to maintain the customers' confidence related to the credibility of the company.

The ninth risk arises from the multiple functiosn between the execution and the checking. This is related to the risk of increasing the amount of credit by the debtors who no longer meet the eligibility standards. The granting of the credit to these debtors will result in a decrease in the quality of the corporate long-term credit repayment. The last risk arises from the dual functions between the authorization and the custodial. This risk is related to the manipulation of overall approval of credit process. The entire credit process includes the nominal of crediting, the debtors' feasibility analysis, and other matters based on important information. This manipulation can cover the illegal activities of the credit department that can harm the company in both short and long term. 
The tenth risks mentioned above can strongly harm the company if the segregation of duties performed does not follow the criteria of proper segregation process. These risks arise when a particular section implements multiple functions to carry out its activities. The risk of any duplicate functions may underlie the emergence of others if it consists of three or more functions within a single department. The risk of triple functions or more is then referred to as the advanced risk.

There are two types of advanced risk in the credit department. The first arises as a result of the multiple functions of execution, checking, and recording in the AO section. The risk includes falsifying a department's in-house activities report to cover illegal activities related to the customers' retention and network expansion, such as falsification of the results of the debtors or prospective debtors' eligibility checks. The second advanced risk in the company occurs as a result of the multiple executions, checking, and recording functions contained in the ADMK section. Such risks include approval of making activity reports related to the loans to the debtors who should not meet criteria or are not eligible for the credit.

The first part of the credit department is $\mathrm{RBO}$. RBO is the marketing section of various banking products available, including credit marketing. Each respondent from the RBO section as a marketer has a tendency to respond to considerable risks. Almost every respondent has his or her views. However, the most common tendency in this section is to share the risks of each employee. This is enough to support the basic concepts related to the character of marketers who are required to be able to work well within teams and build good relations (communicate) with any party. The most basic concept required by the marketer is contained in the job description of RBO's employees in term of position.

The second part of the credit department is $\mathrm{AO}$. AO is a part of credit department that performs all activities related to credit disbursement, including analysis of credit thoroughly. Each respondent from the $\mathrm{AO}$ section as a credit analyst has a clear tendency to respond to the risks of his/her activities. Each respondent from AO shows a tendency to reduce the risks in running each activity. This is also in accordance with the criteria/job requirements contained in the company related to the concept of integrity and caution in carefulness in running its duties. This caution directs every employee not to take bigger risks in carrying out his duties for the achievement of corporate goals.

The third section examined in the credit department is ADMK. ADMK is a credit section that is responsible for the overall credit analysis, especially the credit approval process. Each respondent from the ADMK section, as a credit analyst and the party who approves the credit distribution, has the same obvious tendencies as $\mathrm{AO}$ in responding to the risks and activities. Each respondent in this section shows the tendency to reduce the risk in running each activity. The same tendency to respond to risk in $\mathrm{AO}$ is a consequence of similar responsibilities that both sections have in the credit department. This response appears in ADMK section because in analyzing the credit thoroughly, the company needs the employees who prioritize prudence and integrity in order to improve the quality of credit distribution services for the debtors and prospective loaners.

This study shows a tendency to respond clearly to the risk of each section. The tendency in responding to risk from each of these employees will be the basis for its adjustment toward the types of personality to analyze the suitability between the application of the segregation of corporate duties and the criteria expected by the management. The sections in the credit department which have primary responsibility for a comprehensive credit analysis have a tendency to reduce the risks due to their vital roles in the sustainability of corporate credit disbursement. Meanwhile, the internal sections of the credit department that have a primary focus on product marketing efforts tend to share their risks with others. Cooperations with these other parties can improve the sales productivity as a core of their responsibilities.

A second analysis to assess the suitability of segregation of duties is an analysis of the types of personality of each department. These types of personality analysis will be combined later with 
previous earlier risk response analysis to assess the suitability of the segregation of corporate duties. Table 1 is the results of determining the types of personality in each section of the credit department.

Table 1. Analysis of the Types of Personalities of Each Employee

\begin{tabular}{|c|c|c|c|c|c|c|c|c|c|c|c|c|}
\hline \multirow{3}{*}{ Section } & \multirow{3}{*}{$\#$} & \multicolumn{10}{|c|}{ Determinant Indicators of the Types of Personalities } & \multirow{3}{*}{$\begin{array}{l}\text { Tenden- } \\
\text { cies of the } \\
\text { Types of } \\
\text { Personality }\end{array}$} \\
\hline & & \multicolumn{2}{|r|}{$\mathrm{E}$} & \multicolumn{2}{|r|}{ A } & \multicolumn{2}{|r|}{$\mathrm{N}$} & \multicolumn{2}{|c|}{$\mathrm{C}$} & \multicolumn{2}{|r|}{$\mathrm{O}$} & \\
\hline & & $\sum$ & $\%$ & $\sum$ & $\%$ & $\Sigma$ & $\%$ & $\sum$ & $\%$ & $\Sigma$ & $\%$ & \\
\hline \multirow{22}{*}{$\mathrm{RBO}$} & 1 & 4 & $80 \%$ & 2 & $40 \%$ & 1 & $20 \%$ & 3 & $60 \%$ & 5 & $100 \%$ & $\mathrm{O}$ \\
\hline & 2 & 4 & $80 \%$ & 2 & $40 \%$ & 2 & $40 \%$ & 3 & $60 \%$ & 4 & $80 \%$ & $\mathrm{EO}$ \\
\hline & 3 & 5 & $100 \%$ & 2 & $40 \%$ & 1 & $20 \%$ & 4 & $80 \%$ & 2 & $40 \%$ & $\mathrm{E}$ \\
\hline & 4 & 5 & $100 \%$ & 0 & $0 \%$ & 3 & $60 \%$ & 5 & $100 \%$ & 3 & $60 \%$ & $\mathrm{EC}$ \\
\hline & 5 & 5 & $100 \%$ & 5 & $100 \%$ & 3 & $60 \%$ & 4 & $80 \%$ & 4 & $80 \%$ & EA \\
\hline & 6 & 5 & $100 \%$ & 3 & $60 \%$ & 0 & $0 \%$ & 3 & $60 \%$ & 5 & $100 \%$ & EO \\
\hline & 7 & 5 & $100 \%$ & 1 & $20 \%$ & 1 & $20 \%$ & 5 & $100 \%$ & 4 & $80 \%$ & $\mathrm{EC}$ \\
\hline & 8 & 5 & $100 \%$ & 5 & $100 \%$ & 3 & $60 \%$ & 5 & $100 \%$ & 4 & $80 \%$ & EAC \\
\hline & 9 & 5 & $100 \%$ & 4 & $80 \%$ & 1 & $20 \%$ & 5 & $100 \%$ & 3 & $60 \%$ & EC \\
\hline & 10 & 5 & $100 \%$ & 2 & $40 \%$ & 3 & $60 \%$ & 5 & $100 \%$ & 4 & $80 \%$ & EC \\
\hline & 11 & 5 & $100 \%$ & 3 & $60 \%$ & 1 & $20 \%$ & 4 & $80 \%$ & 5 & $100 \%$ & EO \\
\hline & 12 & 5 & $100 \%$ & 2 & $40 \%$ & 1 & $20 \%$ & 4 & $80 \%$ & 5 & $100 \%$ & EO \\
\hline & 13 & 5 & $100 \%$ & 2 & $40 \%$ & 1 & $20 \%$ & 4 & $80 \%$ & 5 & $100 \%$ & EO \\
\hline & 14 & 5 & $100 \%$ & 2 & $40 \%$ & 1 & $20 \%$ & 4 & $80 \%$ & 5 & $100 \%$ & EO \\
\hline & 15 & 5 & $100 \%$ & 1 & $20 \%$ & 3 & $60 \%$ & 5 & $100 \%$ & 4 & $80 \%$ & $\mathrm{EC}$ \\
\hline & 16 & 4 & $80 \%$ & 1 & $20 \%$ & 2 & $40 \%$ & 3 & $60 \%$ & 3 & $60 \%$ & $\mathrm{E}$ \\
\hline & 17 & 5 & $100 \%$ & 1 & $20 \%$ & 2 & $40 \%$ & 5 & $100 \%$ & 4 & $80 \%$ & EC \\
\hline & 18 & 5 & $100 \%$ & 2 & $40 \%$ & 2 & $40 \%$ & 4 & $80 \%$ & 5 & $100 \%$ & EO \\
\hline & 19 & 4 & $80 \%$ & 2 & $40 \%$ & 1 & $20 \%$ & 5 & $100 \%$ & 4 & $80 \%$ & C \\
\hline & 20 & 3 & $60 \%$ & 0 & $0 \%$ & 2 & $40 \%$ & 5 & $100 \%$ & 4 & $80 \%$ & $\mathrm{C}$ \\
\hline & 21 & 4 & $80 \%$ & 2 & $40 \%$ & 3 & $60 \%$ & 5 & $100 \%$ & 4 & $80 \%$ & C \\
\hline & 22 & 4 & $80 \%$ & 1 & $20 \%$ & 5 & $100 \%$ & 4 & $80 \%$ & 4 & $80 \%$ & $\mathrm{~N}$ \\
\hline
\end{tabular}




\begin{tabular}{|c|c|c|c|c|c|c|c|c|c|c|c|c|}
\hline \multirow{3}{*}{ Section } & \multirow{3}{*}{$\#$} & \multicolumn{10}{|c|}{ Determinant Indicators of the Types of Personalities } & \multirow{3}{*}{$\begin{array}{l}\text { Tenden- } \\
\text { cies of the } \\
\text { Types of } \\
\text { Personality }\end{array}$} \\
\hline & & \multicolumn{2}{|r|}{$\mathrm{E}$} & \multicolumn{2}{|r|}{ A } & \multicolumn{2}{|r|}{$\mathrm{N}$} & \multicolumn{2}{|r|}{$\mathrm{C}$} & \multicolumn{2}{|r|}{$\mathrm{O}$} & \\
\hline & & $\sum$ & $\%$ & $\sum$ & $\%$ & $\sum$ & $\%$ & $\sum$ & $\%$ & $\sum$ & $\%$ & \\
\hline \multirow{7}{*}{$\mathrm{AO}$} & 1 & 5 & $100 \%$ & 2 & $40 \%$ & 2 & $40 \%$ & 5 & $100 \%$ & 4 & $80 \%$ & $\mathrm{EC}$ \\
\hline & 2 & 5 & $100 \%$ & 4 & $80 \%$ & 3 & $60 \%$ & 4 & $80 \%$ & 3 & $60 \%$ & $\mathrm{E}$ \\
\hline & 3 & 5 & $100 \%$ & 4 & $80 \%$ & 4 & $80 \%$ & 5 & $100 \%$ & 4 & $80 \%$ & EC \\
\hline & 4 & 4 & $80 \%$ & 5 & $100 \%$ & 5 & $100 \%$ & 0 & $0 \%$ & 1 & $20 \%$ & $\mathrm{AN}$ \\
\hline & 5 & 5 & $100 \%$ & 2 & $40 \%$ & 3 & $60 \%$ & 5 & $100 \%$ & 4 & $80 \%$ & $\mathrm{EC}$ \\
\hline & 6 & 5 & $100 \%$ & 1 & $20 \%$ & 3 & $60 \%$ & 5 & $100 \%$ & 4 & $80 \%$ & $\mathrm{EC}$ \\
\hline & 7 & 4 & $80 \%$ & 1 & $20 \%$ & 2 & $40 \%$ & 5 & $100 \%$ & 4 & $80 \%$ & $\mathrm{C}$ \\
\hline \multirow{5}{*}{$\begin{array}{l}\text { A D M K } \\
\text { staffs }\end{array}$} & 1 & 5 & $100 \%$ & 3 & $60 \%$ & 3 & $60 \%$ & 5 & $100 \%$ & 4 & $80 \%$ & EC \\
\hline & 2 & 5 & $100 \%$ & 0 & $0 \%$ & 2 & $40 \%$ & 5 & $100 \%$ & 3 & $60 \%$ & $\mathrm{EC}$ \\
\hline & 3 & 5 & $100 \%$ & 1 & $20 \%$ & 1 & $20 \%$ & 5 & $100 \%$ & 4 & $80 \%$ & EC \\
\hline & 4 & 4 & $80 \%$ & 1 & $20 \%$ & 1 & $20 \%$ & 4 & $80 \%$ & 5 & $100 \%$ & $\mathrm{O}$ \\
\hline & 5 & 5 & $100 \%$ & 3 & $60 \%$ & 3 & $60 \%$ & 5 & $100 \%$ & 4 & $80 \%$ & EC \\
\hline
\end{tabular}

Note:

\# $\quad$ : Respondent

$\Sigma \quad:$ Number of in-criteria answers

$\% \quad$ : Percentage of in-criteria answers

E : extraversion personality type

A : agreeableness personality type

$\mathrm{N}$ : neuroticism personality type

C : conscientiousness personality type

$\mathrm{O}$ : openness to experience personality type

EA : Combination between extraversion and agreeableness

EC : Combination between extraversion and conscientiousness

EO : Combination between extraversion and openness to experience

AN : Combination between agreeableness and neuroticism

EAC : Combination between extraversion and agreeableness and conscientiousness

The employees of the RBO section have diverse types of personality and are dominated by a combined personality type between extraversion and openness to experience. This suggests that most RBO employees have optimistic and adaptive attitudes toward various situations. This also indicates that this section tends to respond to the risks by sharing through cooperative processes. The employees of AO and ADMK sections who have similar activities between each other have a personality type of combination between extraversion and conscientiousness. This shows that most of the employees have high optimism but accompanied with carefulness in carrying out their activities. The carefulness makes these two sections are able to respond to more risks by reducing them.

Before analyzing the suitability of the segregation of duties applied based on the expectations of the management, it is better to firstly identify the management's expectations that are adjusted 
to the achievement of the objectives. This data is obtained through an interview process conducted on two parties, consisting of the credit department manager and the branch managers in charge. This interview is conducted with the aim of ensuring the management's expectations toward the employees of the credit department in carrying out their activities. The main questions asked related to the process of identification of the management expectations on the segregation of employees' duties is divided into four. The first question is related to the personal characters required by each section of the credit department. This question is asked to understand what basic traits that can help employees grouping according to the types of personality.

The second question is still related to the determination of personality types with more specific scopes to determine the personality types criteria required from the big five model of personality. This question is raised to provide assertions regarding the direction of the dominant personality types that the company needs in particular sections. The third question concerns the personality types that aim to group the dominant types of personality expected in particular sections of the credit department. The fourth question is specifically about the activities related to how each individual in particular sections responds to the risks that arise. The answers to these questions will be adapted to the personality types they have, to strengthen the analysis of the individual's works in a particular section. Table 3 is the summary of interview results with the corporate management.

Table 2. Results of Identification of Management's Expectation related to Segregation of Duties based on Personality Types and Responses Toward the Risks

\begin{tabular}{lccc}
\hline Source & $\begin{array}{c}\text { Sections of Credit } \\
\text { Departement }\end{array}$ & $\begin{array}{c}\text { Expected Types of } \\
\text { Personality }\end{array}$ & $\begin{array}{c}\text { Expected Responses } \\
\text { Toward the Risks }\end{array}$ \\
\hline Branch Man- & RBO & EO & Share \\
agers & AO & EC & Reduce \\
& ADMK & EC & Reduce \\
Credit Manag- & RBO & EO & Share \\
ers & AO & EC & Reduce \\
& ADMK & EC & Reduce \\
\hline
\end{tabular}

The results of table 2 indicate the expected criteria of the management and the reality of segregation of duties that are implemented on each section of the credit department. The results of the analysis of the risk-related responses are combined with the results of personality type analysis which then becomes a new analytical tool that can be used to measure suitability level. Table 3 is the result of suitability analysis of the implementation process of the separation of corporate duties based on the management's criteria.

Table 3. Analysis Results of Suitability between Segregation of Duties and Criteria of Segregation Expected by the Management

\begin{tabular}{|c|c|c|c|}
\hline \multirow[b]{2}{*}{ Section } & \multicolumn{2}{|l|}{ Criteria } & \multirow[b]{2}{*}{$\begin{array}{c}\text { Percentage of } \\
\text { Suitability }\end{array}$} \\
\hline & Types of Personality & $\begin{array}{l}\text { Responses to- } \\
\text { ward the Risks }\end{array}$ & \\
\hline $\mathrm{RBO}$ & Extraversion - Openness to experience & Share & $13.64 \%$ \\
\hline $\mathrm{AO}$ & Extraversion-Conscientiousness & Reduce & $57.14 \%$ \\
\hline ADMK & Extraversion - Conscientiousness & Reduce & $80 \%$ \\
\hline
\end{tabular}

Source: Author's Processed Questionnaire Results

The management has certain expectations regarding the criteria of segregation of employees' 
duties from these three sections in terms of personality types possessed by certain individuals and responses toward the risks. The management has extraversion and openness to experience criteria for RBO with sharing the risks related to the concept of developed cooperations. The percentage of suitability of the segregation of the applied functions assessed from the personality types and the responses toward the risks from the RBO is $13.64 \%$. This shows that the employee' placement related to segregation of duties in the credit department section RBO is still not in accordance with the management's expectation. The RBO section has too many employees with the personality types and how to respond to various risks. This situation may cause difficulties for the company related to the achievement of targets due to the characters of the employees who are less supportive with their activities. The company needs to pay more attention to the quality of the employees' recruitment section of $\mathrm{RBO}$ if the productivity of the banking products selling, especially the credit section, wants to be maintained or enhanced.

The management has the criteria of extraversion and conscientiousness for the $\mathrm{AO}$ section with the risk responses that is to reduce the risks related to the concept of carefulness in the process of credit verification entirely. The percentage of suitability of the applied duties segregation assessed from the personality types and the responses toward the risk of the AO section is $57.14 \%$. This indicates that the employees' placement related to segregation process of the credit department of $\mathrm{AO}$ section has been appropriate in accordance with teh management's expectation. Four of the seven AO staff members who run their activities already have an appropriate personality, specifically in terms of responding toward the risks that may arise from the activities. This also shows that the effort to maintain the quality of activities as the main focus of the company is really noticed optimally, specifically related to the placement of employees.

Meanwhile, for the last section of the ADMK, the management has the same personality types criteria in the $\mathrm{AO}$ section i.e. extraversion and conscientiousness related to the concept of carefulness in the process of credit lending. The percentage of suitability of the segregation of the applied duties assessed from the personality types and the responses toward the risk of ADMK staffs is $80 \%$. This indicates that the employees' placement related to the process of segregation of the functions of the credit department in the ADMK section is already good, in accordance with the management's expectations, as well as the AO section. Four of the five ADMK staffs who run their activities already have appropriate personality types in terms of responding toward the risks arising from the activities. This section has the percentage of appropriateness of applying the highest function segregation from the other two toward the expected management criteria. This indicates that the activities undertaken by this section have good conformity to the overall corporate objectives, not just to the department's personal goals.

\section{CONCLUSIONS}

The research results show that Relationship Banking Officer unit in credit department does not meet management expectations. This unit has too many employees with various personality types and different respond to risks. Employee' placement related to segregation of duties in the credit department section RBO is still not in accordance with the management's expectation.

Meanwhile, the employee placement at Account Officer unit in credit department has met the management expectation as well as the employee placement at Administration Staff Credit unit. Four of the seven AO staff members who run their activities already have an appropriate personality, specifically in terms of responding toward the risks that may arise from the activities. It can be concluded that the procedure of function separation in credit department has been done in accordance with the criteria of the management. Four of the five ADMK staffs who run their activities already have appropriate personality types in terms of responding toward the risks arising from the activities

The limitation of this research is the limited sample used by researchers. In addition, the results of this study have the potential difference in results if implemented in other banks. Because 
each bank can have special characteristics.

\section{REFERENCES}

Abbott, L. J., Parker, S., Peters, G. F., \& Rama, D. V. (2007). Corporate Governance, Audit Quality, and the Sarbanes-Oxley Act: Evidence from Internal Audit Outsourcing. The Accounting Review, 82(4), 803-835.

Agbejule, A., \& Jokipii, A. (2009). Strategy, Control Activities, Monitoring and Effectiveness. Managerial Auditing Journal, 24(6), 500-522.

Arens, A. A., Elder, R. J., \& Mark, B. (2012). Auditing and Assurance Services : an Integrated Approach (15th ed.). Harlow: Boston: Prentice Hall.

Ayub, N., Ayub, N., AlQurashi, S. M., AlQurashi, S. M., Al-Yafi, W. A., Al-Yafi, W. A., ... Jehn, K. (2017). Personality Traits and Conflict Management Styles in Predicting Job Performance and Conflict. International Journal of Conflict Management, 28(5), 671-694.

Bakker, A. B., Boyd, C. M., Dollard, M., Gillespie, N., Winefield, A. H., \& Stough, C. (2010). The Role of Personality in the Job Demands-Resources Model: A Study of Australian Academic Staff. Career Development International, 15(7), 622-636.

Chen, T.-Y. (2008). Knowledge Sharing in Virtual Enterprises Via an Ontology-Based Access Control Approach. Computers in Industry, 59(5), 502-519.

Church, A. H., Rotolo, C. T., Margulies, A., Del Giudice, M. J., Ginther, N. M., Levine, R., ... Tuller, M. D. (2015). The Role of Personality in Organization Development: A Multi-Level Framework for Applying Personality to Individual, Team, and Organizational Change. In Research in organizational change and development (pp. 91-166). Emerald Group Publishing Limited.

Doyle, J., Ge, W., \& McVay, S. (2007). Determinants of Weaknesses in Internal Control Over Financial Reporting. Journal of Accounting and Economics, 44(1), 193-223.

Ettredge, M. L., Li, C., \& Sun, L. (2006). The Impact of SOX Section 404 Internal Control Quality Assessment on Audit Delay in the SOX Era. Auditing: A Journal of Practice \& Theory, 25(2), 1-23.

Galenianos, M., \& Kircher, P. (2009). Directed Search with Multiple Job Applications. Journal of Economic Theory, 144(2), 445-471.

Ge, W., \& McVay, S. (2005). The Disclosure of Material Weaknesses in Internal Control after the SarbanesOxley Act. Accounting Horizons, 19(3), 137-158.

George, J. M., Jones, G. R., \& Sharbrough, W. C. (2002). Understanding and Managing Organizational Behavior (3rd ed.). New Jersey: Prentice Hall Upper Saddle River, NJ.

Henri, J.-F. (2004). Performance Measurement and Organizational Effectiveness: Bridging the Gap. Managerial Finance, 30(6), 93-123.

Hussain, S. M. W., \& Hussain, M. (2014). Factors Influencing the Employees' Job Placement Through Recruitment Agencies in Karachi, Pakistan. KASBIT Journal of Management \& Social Science, 7(2), 79-106.

Jørgensen, B., \& Messner, M. (2009). Management Control in New Product Development: The Dynamics of Managing Flexibility and Efficiency. Journal of Management Accounting Research, 21(1), 99-124.

Kavoo-Linge, T., \& Kiruri, J. K. (2013). The Effect of Placement Practices on Employee Performance in Small Service Firms In The Information Technology Sector In Kenya. International Journal of Business and Social Science, 4(15), 85-99.

Marucci-Wellman, H. R., Willetts, J. L., Lin, T.-C., Brennan, M. J., \& Verma, S. K. (2014). Work in Multiple Jobs and the Risk of Injury in the US Working Population. American Journal of Public Health, 104(1), 134-142.

McCrae, R. R. (2002). Cross-Cultural Research on the Five-Factor Model of Personality. Online Readings in Psychology and Culture, 4(4), 1-12.

Moeller, R. R. (2008). Sarbanes-Oxley internal controls: effective auditing with AS5, CobiT, and ITIL. New Jersey: John Wiley \& Sons.

San Park, J., \& Hyun Kim, T. (2009). Do Types of Organizational Culture Matter in Nurse Job Satisfaction and Turnover Intention? Leadership in Health Services, 22(1), 20-38.

Vaassen, E., Meuwissen, R., \& Schelleman, C. (2009). Accounting information systems and internal control. Chichester: Wiley Publishing. 